\title{
POTENSI “IKAN MURAI AIR TAWAR" (Gymnothorax polyuranodon) SEBAGAI IKAN HIAS
}

\author{
Ahmad Musa, Bastiar Nur, dan Rina Hirnawati \\ Balai Riset Budidaya Ikan Hias \\ Jl. Perikanan No. 13, Pancoran Mas, Depok \\ E-mail: ahmadmusasaid@yahoo.co.id
}

\begin{abstract}
ABSTRAK
Indonesia merupakan negara yang kaya akan potensi sumberdaya alam hayati termasuk di dalamnya ikan-ikan air tawar, payau, dan laut yang prospeknya dikembangkan sebagai komoditas yang bernilai ekonomi tinggi. Ikan murai air tawar (Gymnothorax polyuranodon) merupakan salah satu spesies ikan yang sebarannya cukup luas di Indonesia. Dalam siklus hidupnya ikan murai ini hidup di air tawar, payau dan laut. Corak warna coklat kekuningan dengan bintik hitam bulat yang tidak teratur pada kepala seperti pita-pita yang warnanya memanjang yang lengkap serta bentuknya yang mirip ular menyebabkan ikan murai ini juga dijadikan ikan hias. Tiga kali koleksi ikan murai di alam telah dilakukan di Sungai Lasusua, Sulawesi Tenggara pada September 2008, Oktober, dan November 2009.
\end{abstract}

KATAKUNCI: potensi, murai air tawar, Gymnothorax polyuranodon, ikan hias

\section{PENDAHULUAN}

Indonesia merupakan negara yang kaya dengan potensi sumberdaya ikan baik tawar maupun laut, saat ini 1.168 spesies ikan air tawar dan 3.430 spesies ikan air laut (www.fishbase.org). Banyaknya sumberdaya ikan ini merupakan keuntungan di mana terbuka banyak peluang untuk memunculkan kandidat ikan budidaya terutama di bidang ikan hias. Salah satu spesies yang memiliki peluang untuk dijadikan kandidat ikan hias di Indonesia adalah ikan murai air tawar (Gymnothorax polyuranodon), yang sudah cukup populer di luar negeri.

\section{Potensi}

Corak warna yang sangat menarik menjadi alasan mengapa ikan ini dijadikan sebagai ikan hias. Penduduk lokal menakuti ikan ini dikarenakan bentuknya yang mirip ular dan dugaan akan racunnya (Haryono \& Tjakrawidjaja,
2004). G. polyuranodon karena bentuknya yang seperti ular inilah dianggap sebagai ular air. Hal tersebut pula yang menyebabkan ikan ini tidak dikonsumsi. Adapula masyarakat yang tidak mengkonsumsi dikarenakan kepercayaan bahwa ikan tersebut adalah nenek moyang dari A. marmorata (Musa et al., 2010). Dengan demikian ikan ini hanya betul-betul bisa dimanfaatkan sebagai ikan hias (www.fishbase.org).

Dari segi nilai ekonomi, harga ikan ini cukup tinggi, di kalangan hobiis luar negeri harganya bisa mencapai US\$100 (www.monsterfishkeepers.com). Namun di Indonesia, ikan ini belum populer karena kurangnya informasi akan nilai ekonominya.

\section{Klasifikasi dan Psikologi Ikan Murai}

Nama umum ikan ini adalah "Freshwater Moray" atau"Spotted Freshwater Moray Eel", adapun di Indonesia nama lokalnya berbeda-beda, di Sulawesi Utara disebut Bibinanga (Haryono \& Tjakrawidjaja, 2004), di Sulawesi Tenggara disebut Binnuang (Musa et al., 2010). Di Sulawesi Utara ikan ini ditemukan di Ongkak, Sungai Dumoga (Haryono \& Tjakrawidjaja, 2004). Celah mulut ikan ini kira-kira 3,5 kali lebih pendek dari panjang kepala. Panjang kepala 4-5 kali lebih pendek dari panjang badan. Warna badan coklat kekuningan dengan bintik-bintik hitam bulat yang tidak teratur dan pada kepala berubah seperti pitapita warna memanjang yang lengkap (Kottelat et al., 1993). Panjang maksimal yang pernah ditemukan adalah $150 \mathrm{~cm}$ serta dapat ditemui di air tawar sepanjang musim (Ebner et al., 2011). Umur ikan ini di habitat aslinya dapat mencapai 8-12 tahun (www.theaquariumwiki.com).

Ikan ini bersifat demersal. Dengan klasifikasinya:

Kingdom : Animalia

Phylum : Chordata

Kelas : Osteichthyes

Ordo : Anguilliformes

Famili : Muraenidae

Genus : Gymnothorax

Spesies : Gymnothorax polyuranodon (Bleeker, 1853) 


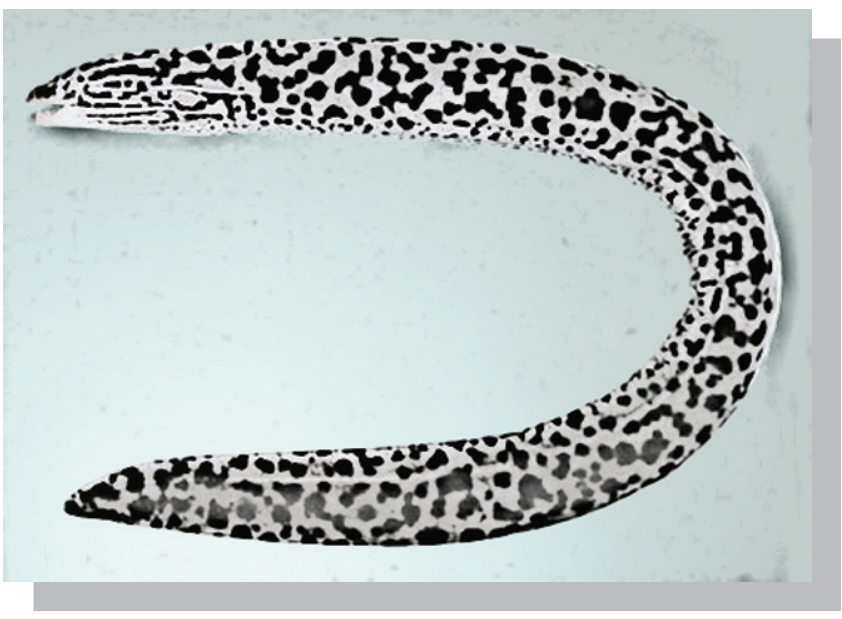

Gambar 1. Ikan murai air tawar (Gymnothorax polyuranodon) (sumber: www.eol.org)

Murai air tawar berada dalam famili Muraenidae di bawah ordo Anguilliformes, suku murai ini paling banyak terdapat dan tersebar luas di antara berbagai jenis sidat, dan lebih banyak ditemukan di laut tropis dan kawasan beriklim sedang. Pada umumnya memiliki sirip punggung dan sirip dubur yang berkembang baik tetapi tidak mempunyai sirip dada dan sirip perut. Beberapa jenis sangat panjang, dapat mencapai tiga meter. Satu jenis Thyrsoidea macrurus yang memasuki habitat sungai-sungai di Indonesia mungkin merupakan jenis yang terpanjang di dunia. Murai besar ini dapat membahayakan jika diganggu walaupun umumnya tidak begitu berbahaya dan gigitannya tidak beracun jika panjangnya kurang dari satu meter. Banyak jenis yang berwarna cerah dan memiliki pola warna yang mencolok (Kottelat, 1993).

\section{Habitat Hidup}

Meskipun disebut murai air tawar, namun ikan ini terdapat di air tawar, muara, dan laut. Biasanya murai ditemukan di perairan 20-30 km dari laut pada ketinggian maksimum sekitar 30-40 m di atas permukaan laut. Penyebarannya mulai dari Kepulauan Solomon (Boseto et al., 2007), Sri Lanka, Indonesia, Papua Nugini, Filipina, dan Fiji. Juga dilaporkan ada di Palau, Australia, dan New Caledonia (www.zipcodezoo.com). Ikan ini bersifat katadromous, yang migrasinya besar di air tawar dan ke laut untuk bertelur (www.eol.org).

Suhu air sungai Lasusua, tempat ikan ini ditemukan berkisar antara $23,8^{\circ} \mathrm{C}$ hingga $24,3^{\circ} \mathrm{C}$ dengan pH antara $8,2-8,3$. Salinitas air sungai $0 \mathrm{ppt}$ setelah $500 \mathrm{~m}$ dari muara. Pada saat pasang, air laut masuk ke sungai tidak lebih dari $200 \mathrm{~m}$ (Musa et al., 2010). Kondisi air sungai pada musim kemarau bening dengan arus yang cukup deras. Sungai ini sudah mulai terancam dikarenakan kegiatan

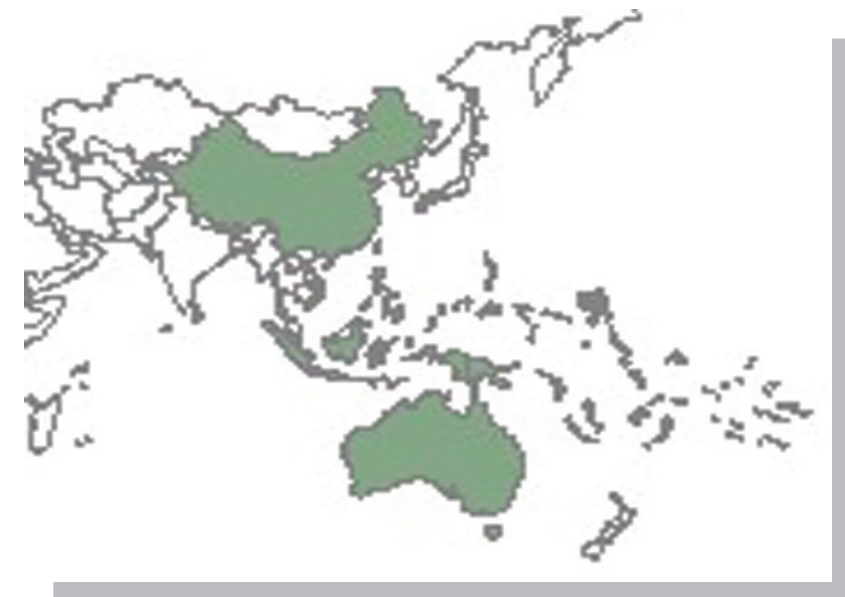

Gambar 2. Area distribusi (berwarna gelap) ikan G. polyuranodon (www.zipcodezoo.com)

penambangan yang berlangsung di sekitar sungai tersebut. Penambangan pasir dan batu kali merupakan ancaman utama yang dikhawatirkan dapat mengganggu kelestarian biota yang terdapat di sungai tersebut (Musa et al., 2010).

Menurut Aquaticcommunity dalam pemeliharaan ikan ini, sebaiknya digunakan akuarium yang besar dengan cukup banyak tempat persembunyian, dapat menggunakan pipa PVC atau batu karang. Berikut kondisi pemeliharaan yang direkomendasikan oleh theaquariumwiki (Tabel 1).

Meski disebut murai air tawar, namun untuk pemeliharaan dianjurkan dengan penambahan salinitas karena ikan ini bersifat katadromous. Dengan penambahan pasir dan karang diharapkan akan meningkatkan kesadahannya.

Tabel 1. Kondisi pemeliharaan untuk G. polyuranodon

\begin{tabular}{lc}
\hline \multicolumn{1}{c}{ Parameter } & Nilai \\
\hline Ukuran air $(\mathrm{L})$ & 378,5 \\
Salinitas $(\mathrm{sg}) / \mathrm{psu}{ }^{*}$ & $1.008-1.012 / 13-19$ \\
$\mathrm{pH}$ & $8,0-8,5$ \\
Suhu $\left({ }^{\circ} \mathrm{C}\right)$ & $25,6-28,9$ \\
Kesadahan $\left({ }^{\circ} \mathrm{d}\right)$ & $8-12$ \\
\hline
\end{tabular}

Sumber: www.theaquariumwiki.com

Specific gravity dikonversi menjadi practical salinity unit pada $25^{\circ} \mathrm{C}$ yang didefinisikan sebagai rasio konduktivitas sampel air laut terhadap larutan $\mathrm{KCl}$ standar

\section{Koleksi dan Adaptasi}

Hingga saat ini kegiatan survai baru berhasil mengoleksi sampel ikan ini dalam bentuk awetan (Haryono \& Tjakrawidjaja, 2004). Belum ada sampel hidup yang didapatkan untuk diadaptasi. Musa et al. (2008 \& 

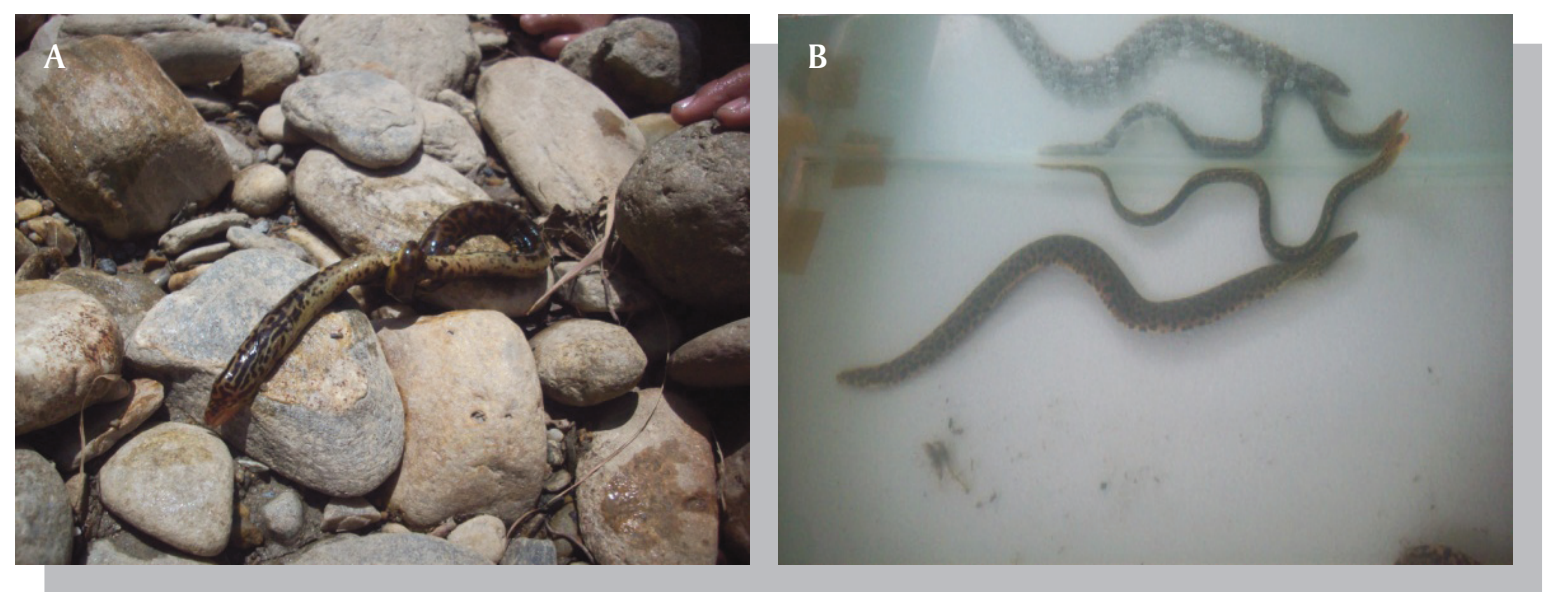

Gambar 3. (a) G. polyuranodon sesaat setelah dikoleksi dari habitat aslinya (b) adaptasi dalam akuarium (Sumber: dokumentasi pribadi)

2010) melakukan koleksi dari Sungai Lasusua, Sulawesi Tenggara pada September 2008, Oktober, dan November 2009 dengan menggunakan alat setrum ikan. Semua ikan yang ditangkap dimasukkan ke dalam wadah tong untuk ditampung dalam keadaan hidup. Ikan dimasukkan ke dalam plastik, sebelumnya ikan diberi bantuan oksigen. Plastik yang berisi ikan hidup kemudian dikumpulkan dalam boks styrofoam dan dibawa ke Balai Riset Budidaya Ikan Hias (BRBIH) Depok.

Dari tiga tahap koleksi, hanya tahap terakhir (November 2010) yang bisa hidup sampai ke BRBIH Depok. Tiga ekor murai air tawar yang berhasil hidup dipelihara dalam akuarium ukuran $100 \mathrm{~cm}$ x $40 \mathrm{~cm}$ x $40 \mathrm{~cm}$, dengan ketinggian air $30 \mathrm{~cm}$.

Pakan yang diberikan berupa ikan seribu, udang air tawar, dan cacing tanah, dan tampaknya pakan yang lebih disukai dan sering dimakan adalah udang air tawar. Sayangnya dalam empat pekan ikan ini mati mungkin karena masih sulit beradaptasi dengan lingkungan akuarium (Musa et al., 2010).

\section{Kendala dan Tantangan}

Ikan ini belum pernah dipijahkan dalam pemeliharaan (www.fishprofiles.com), dan perbedaan jenis kelaminnya sangat sukar diamati secara visual (www.fishbase.org). Kendala dalam pemeliharaan adalah sifatnya yang nokturnal yaitu aktif mencari makan di malam hari, pemalu, dan mudah stres hingga sangat susah untuk makan dalam pemeliharaan (www.theaquariumwiki.com) bahkan sering tidak makan hingga 2-3 bulan jika dalam keadaan stres (www.aquaticcommunity.com).

Adaptasi terhadap kualitas air juga menjadi kendala, di mana ikan ini juga dapat hidup di air payau dan laut, hingga dikhawatirkan air yang digunakan saat pemeliharaan membuat ikan ini stres dan mudah terkena penyakit bahkan kematian. Faktor pakan, kendalanya adalah karena penglihatan ikan ini hampir tidak berfungsi, maka pakan yang diutamakan adalah pakan yang memiliki bau khas. Dan karena hanya mengandalkan penciuman, terkadang ikan ini menyerang ikan lain karena baunya yang menyerupai bau pakan. Ikan ini juga memiliki kemampuan untuk hidup di luar air untuk beberapa saat dan bisa keluar dari wadah, hingga diperlukan penutup akuarium yang tidak berlubang (www.theaquariumwiki. com).

\section{DAFTAR ACUAN}

Boseto, D., Morrison, C., Pikacha, P., \& Pitakia, T. 2007. Biodiversity and conservation of freshwater fishes in selected rivers on Choiseul Island, Solomon Islands, The South Pacific J. of Natural Science, 3: 16- 21.

Ebner, B.C., Kroll, B., Godfrey, P., Thuesen, P.A., Vallance, T., Pusey, B., Allen, G.R., Rayner, T.S., \& Perna, C.N. 2011. Is the elusive Gymnothorax polyuranodon really a freshwater moray?, J. of Fish Biology, 79: 70-79.

Haryono \& Tjakrawidjaja, A.H. 2004. Studies on the freshwater fishes of North Sulawesi, Puslat Litbang Biologi LIPI, Bogor, $120+$ vi hlm.

http://www.aquaticcommunity.com/predatory/fresh watermoray.php (diakses tanggal 17 November 2011).

http://www.eol.org/pages/224288/overview (diakses tanggal 17 November 2011).

http://www.fishbase.org/Country/CountryChecklist. php?c_code $=360 \&$ vhabitat $=$ all $2 \&$ csub_code $($ diakses tanggal 11 November 2011).

h t t p :// w w w. fis h bas e.org/s u m mary/ speciessummary.php?id $=17227$ (diakses tanggal 17 
November 2011).

http://www.fishprofiles.com/profiles/freshwater/ OthersFW/Gymnothorax_polyuranodon/ (diakses tanggal 17 November 2011)

http://www.monsterfishkeepers.com/forums/ showthread.php?142269-FreshWater-Morays-EelsGymnothorax-polyuranodon\&p=2578773 (diakses tanggal 17 November 2011).

h t t p : // w w w. the a quarium wi ki.com/ Gymnothorax_polyuranodon (diakses tanggal 17 November 2011).

http://www.zipcodezoo.com/Animals/G/ Gymnothorax_polyuranodon/ (diakses tanggal 17 November 2011).
Kottelat, M., Whitten, A.J., Kartikasari, S.N., \& Wirjoatmodo, S. 1993. Freshwater fishes of western Indonesia and Sulawesi, Periplus edition, Indonesia, $293+84 \mathrm{hlm}$.

Musa, A., Fahmi, M.R., \& Nur, B. 2008. Beberapa Jenis Ikan di Sungai Lasusua, Kolaka Utara, Sulawesi Tenggara. Prosiding Seminar Nasional Perikanan Indonesia 2008, Sekolah Tinggi Perikanan Jakarta, 4-5 Desember 2008, hlm. 341-345.

Musa, A., Nur, B., \& Bongi. 2010. Koleksi dan Adaptasi Ikan Hias Asli Sungai Lasusua, Sulawesi Tenggara, untuk Kandidat Budidaya Ikan Hias. Prosiding Seminar Nasional Biologi 2010. Fakultas Biologi Universitas Gadjah Mada, ISBN : 978-979-8969-05-8. 